\title{
A Prospective Observational Study on Clinico - Pathological Correlation in Polymorphous Light Eruption
}

\author{
Karpagam Baliah ${ }^{1}$, Karunakaran Maduravasagam $^{2}$, Lakshmi Radhakrishnan ${ }^{3}$, \\ Jayasri Jambulingam ${ }^{4}$ \\ ${ }^{1}$ Assistant Professor, Department Of Dermatology, Tiruvannamalai Medical College, Tiruvannamalai. \\ ${ }^{2}$ Professor, Department Of Dermatology, Tiruvannamalai Medical College, Tiruvannamalai. \\ ${ }^{3}$ Senior Resident, Department Of Dermatology, Tiruvannamalai Medical College, Tiruvannamalai. \\ ${ }^{4}$ Senior Resident, Department Of Dermatology, Tiruvannamalai Medical College, Tiruvannamalai.
}

\begin{abstract}
Introduction: Sun exposure is widely felt to induce a sense of well - being. But there are also abnormal responses to Sunlight. This study highlights the clinico - pathological correlation in polymorphous light eruption, one of the abnormal responses of sunlight exposure.

Materials And Methods: This study was a prospective and observational study conducted in Department of Dermatology, GTVMCH, during the period of March.2016 to August - 2016. Patients with skin types I to VI were assessed and type of lesions were analyzed morphologically and histopathologicaly.

Results And Conclusion: Incidence of PMLE was 3.6\% commonest age of incidence was 21-30 years. Females, housewives were the commonest affected. Plaque type was the commonest morphological type, followed by papule, patch and LN type. The HPE correlated with the morphological type. Patents with Skin type IV Were commonest to be affected.
\end{abstract}

\section{Introduction}

Almost every ancient civilization worshipped sun, whose healing powers were believed to be broad reaching. Even today, sun exposure is widely felt to induce a sense of well being . In addition sunlight is important for the synthesis of vitamin $\mathrm{D}_{3}$. On the negative side, sunlight causes deleterious acute and chronic effects such as sunburn, skin cancer, and photoaging, and can elicit adverse reactions to certain drugs. Abnormal responses to sunlight occur in polymorphous light eruption, solar urticaria, certain porphyrias, and many other conditions.

While the sun is a major source of UVand visible radiation that interacts with human skin, they are also emitted from common sources such as fluorescent lights, incandescent bulbs, phototherapy lambs. Thus, UV and visible radiation are a constant part of the human environment and play a role in health, disease, and therapy. Photobiology is a study of this interaction between human tissues and UV or visible radiation, usually from the sun, but from artificial sources as well.

\section{Materals And Methods}

All the new patients attending the Dermatology OP at GTVMCH Tiruvannamalai during the period between March - 2016 to August - 2016 were screened and patients with PMLE were enrolled. Patients etails recorded included month and age of onset of symptoms of PMLE, its severity, nature - transient, persistent or recurrent, aggravating factors, constitutional and other symptoms, results of healing of the rash and any change in the severity of symptoms. Family history, the patient's occupation, duration of exposure to sunlight during outdoor activities including travel, preference for the type of clothing; materials used during daytime cosmetics and sunscreens, as well as types of previous treatments were noted.

\section{Inclusion Criteria}

The inclusion criteria included patients between the age group 10-60 years and the patients without systemic ailments, people living at an accessible distance to GTVMCH.

\section{Exclusion Criteria}

The exclusion criteria included patients less than 10 and more than 60 years, subjects taking systemic cortico steroids or photo sensitizing drugs and immunosuppressants. 
Incidence

\section{Observation And Results}

Out of total 10779 new patients attending skin OP GTVMCH during the period between March-16August-16,the number of patients with PMLE was 388.

Incidence of PMLE was 3.6\% The ages of the patients varied from 10-60 years. Out of the above patients, 100 patients with PMLE as per the inclusion and exclusion criteria were taken up for the study.

Table - 1 Distribution According To Age

\begin{tabular}{|c|c|c|c|c|}
\hline Age & Males & Females & Male\% & Female\% \\
\hline $11-20$ & 9 & 14 & 39.1 & 60.9 \\
\hline $21-30$ & 12 & 25 & 32.4 & 67.6 \\
\hline $31-40$ & 6 & 10 & 37.5 & 62.5 \\
\hline $41-50$ & 5 & 7 & 41.6 & 58.4 \\
\hline $51-60$ & 5 & 6 & 45.4 & 54.6 \\
\hline
\end{tabular}

Commonest age of incidence 21-30 (37\%)

\section{Distribution According To Sex}

Total number of cases -100

Total number of females-63

Total number of males-37

Incidence is more common in females

Table-2 Prevalence Of Pmle In Various Occupations

\begin{tabular}{|c|c|c|}
\hline Occupation & Males & Females \\
\hline Agricultural labourers & 18 & 12 \\
\hline House wives & - & 44 \\
\hline Students & 6 & 5 \\
\hline Teachers & - & 2 \\
\hline Driver & 3 & - \\
\hline Mason & 8 & - \\
\hline Shop Keepers & 2 & - \\
\hline
\end{tabular}

Housewives were the commonest to be affected by PMLE

Table-3 To Study Commonest Site

\begin{tabular}{|c|c|c|}
\hline Site & Number of patients & Percentage \\
\hline Forearms & 45 & $45 \%$ \\
\hline Neck & 30 & $30 \%$ \\
\hline Back & 15 & $15 \%$ \\
\hline Face & 10 & $10 \%$ \\
\hline
\end{tabular}

Forearm was found to be the commonest site.

Table - 4 Types Of Pmle And Their Incidence

Total number of cases $-\mathbf{1 0 0}$

\begin{tabular}{|c|c|c|}
\hline Clinical Types & Number of Cases & $\%$ \\
\hline Plaque & 56 & $56 \%$ \\
\hline Papule & 14 & $14 \%$ \\
\hline Patch & 26 & $26 \%$ \\
\hline Lichen nitidus like & 4 & $4 \%$ \\
\hline
\end{tabular}

Plaque type PMLE was the commonest morphological type.

Table - 6 Skin Photo Type Associated With Pmle

\begin{tabular}{|c|c|c|}
\hline Skin type & Number of Cases & $\%$ \\
\hline I & 2 & 2 \\
\hline II & - & - \\
\hline III & 8 & 8 \\
\hline IV & 45 & 45 \\
\hline V & 27 & 27 \\
\hline VI & 18 & 18 \\
\hline
\end{tabular}

The incidence is common in type IV skin photo type 
The ages of the patients varied from $10-60$ years. The ages of 56 patients were $\leq 30$ years $(56 \%)$ and the ages of 43 cases were between 31-70 years (43\%). 44 cases were housewives, 30 were agricultural labourers, 11 were students, 2 were teachers, 3 were drivers, 8 were mason and 2 were shopkeepers. Skin rash was present in all cases along with itching in 51, burning sensation in 20, both itching and burning in 16 , while 13 were asymptomatic. Constitutional symptoms like fever and malaise were present in 11 cases, headache in 3 , swelling of the face in 1 . The rash appeared on exposure to sunlight within 30 minutes in 45 cases and after $>$ *30 minutes in 20 cases, after the sun exposure in 20, but the time interval was not known in 15 patients. The aggravating factor was sunlight in all cases. The skin type of patients varied form III to VI with a maximum of $45(45 \%)$ cases in type IV, $27(27 \%)$ in V, $18(18 \%)$ in VI and only $2(2 \%)$ in type I. Exposed parts were involved in all cases. Forearm was the commonest site to be affected. Most of the cases had plaque type of PMLE.

Biopsy was done in all the four morphological types which showed the following features. In plaque type of PMLE, the epidermis showed hyperkeratosis, well formed granular layer, papillomatosis, increased pigment basal layer. The upper and middermis showed patchy Inflammatory infiltrate. In the patch type, the epidermis was thinned out with increased pigment basal layer. The dermis showed patchy inflammatory infiltrate. In the LN type there was sub - epidermal focal collection of inflammatory infiltrate. Above the infiltrate the epidermis is thinned out. Epidermis in other areas showed irregular acanthosis, with increased pigment basal layer. In the papular type the epidermis showed mild hyperkeratosis, spongiosis, mild acanthosis. The dermis showed patchy inflammatory infiltrate.

\section{Discussion}

PMLE is considered to be a disease of fair skinned individuals with skin types I to IV. In our study, $98 \%$ of the patients were of skin type IV to $\mathrm{VI}^{1}$. This is consistent with the study conducted by Lata Sharma, A.Basnet et $\mathrm{al}^{2}$ which showed a prevalence of $96 \%$ in type IV to VI. The majority of the cases were in the age group of 21-30 years consistent with the report that PMLE is a disease of first three decades of life ${ }^{2}$. This figure coincided with the study of Mastalier $\mathrm{U}_{\text {et }} \mathrm{al}^{3}$ which revealed the mean age of onset at 26 years. Of the cases suffering from PMLE, $63 \%$ were females which coincided with $62 \%$ of female incidence in the study of Jansen et $\mathrm{al}^{4}$ and $68 \%$ incidence in the study of Boonstra et $\mathrm{al}^{5}$. Most of them were housewives $(70 \%)$ in whom exposure to sunlight was intermittent and for ashort period. This finding was consistent with study of Lata Sharma, A. Basnet et al. The clothing used was light which gave full exposure to the neck, arms, fore arms. PMLE lesions fade off sharply at the borders of garments but not all exposed areas are involved. It is thought that exposure of those areas throughout the year makes them more tolerant ${ }^{6}$.

Consistent with the report by Jansen et $\mathrm{al}^{4}$, we found that a $30 \mathrm{~min}$ exposure to sunlight was required to produce the rash, the interval being slightly less than $1 / 2 \mathrm{hr}$ in $31 \%$ cases, more than $1 / 2 \mathrm{hr}$ in $11 \%$ but $58 \%$ were not aware of this.

The external aspect of arms and forearms were involved in most of the cases (45\%), possibly because these parts are placed horizontally while sitting or traveling and receive the maximum exposure. On the other hand, the position of the face is vertical while walking or working or it may not even be exposed to the sun if the person is bending forward. The exposure of the covered areas in the summer months makes them vulnerable to this photodermatoses. Our observation was consistent with the study of Lata Sharma, A. Basnet et al which also showed that the extensor aspect of arms and forearms were involved in most of the cases. The rash was recurrent in $75 \%$ of case as to that of 99 cases in the study by Lata Sharma, A.Basnet et al. The commonest morphological type of lesion noted was the plaque type. This was consistent with the study reported by Hawk which also showed the plaque type as the commonest one ${ }^{7}$. In the study of Boonstra et al, papular type was the commonest and the eczematous type was the rarest. Fewer cases had itching, burning and constitutional symptoms than reported by Frain- Bell et $\mathrm{al}^{8}$. Covered areas were not affected irrespective of the type of clothing or weave tightness which suggests that it is probably preventable by all types of clothing ${ }^{4}$.

The histopathological features of PMLE varied according to the type biopsied. Plaque type showed hyperkeratosis, acanthosis, papillomatosis. Patch type showed thinned out epidermis. Papular type had mild hyperkeratosis and acanthosis. LN type had sub-epidermal focal collection of infiltrate. The other three types showed the similar dermal features-patchy and periappendageal infiltrate. This is consistent with the study of Holzle $\mathrm{EPML}^{9}$ and van prag MC et $\mathrm{al}^{10}$.

\section{Conclusion}

1. The incidence of PMLE attending our, GTVMCH during the period March 16 - August -16 was $3.6 \%$

2. Females were more common to be affected by PMLE.

3. The maximum number of patients were in the age group of 21 to 30 years.

4. The commonest morphology was plaque type followed by patch, papule and LN respectively.

5. The most common site of predilection was forearm followed by neck, back and face. 
6. Housewives were the commonest to be affected followed by agricultural labourers.

7. The histopathological features varied according to the morphological type. The plaque type had hyperkeratosis, acanthosis and papillomatosis. The Patch type had thinned out epidermis. The papular type with mild hyperkeratosis and acanthosis. The dermis in all the above 3 types showed patchy and periappendageal inflammatory infiltrate. LN type showed focal subepidermal collection of lymphocytic inflammatory infiltrate. In the papular type the epidermis showed mild hyperkeratosis, spongiosis, mild acanthosis. The dermis showed patchy inflammatory infiltrate.

8. The patients with skin type IV were the commonest to be affected.

\section{Bibliography References}

[1]. Ros AM, Wennerston G. Current aspects of polymorphous light eruption in Sweden. Photodermatol 1986;3:298-302

[2]. Lat Sharma Basnet A et al.A clinico epidemiological study of polymorphic light eruption. Indian J Dermatol Venereol Leprol 2008;74:15-7.

[3]. Mastalier U, Kerl H, Wolf P. Clinical, Laboratory, phototest and Phototherapy findings in polymorphous light eruption: A retrospective study of 133 patients. Eur J Dermatol 1998;8:554-559.

[4]. Jansan CT. The natural history of polymorphous light eruptions. Arch Dermatol 1979;115:165-179.

[5]. Boonstra HE, van Weelden H, Toonstra J.Van Vloten WA. Polymorphous light eruption. A clinical, photobiologic and follow up study of 110 patients. J AM Acad Dermatol 2000;42:199-207.

[6]. Ting WW, Vest CD, Sontheimer R et al. Practical and experimental consideration of sun protection in dermatology. Int J Dermatol 2003;42:505-13.

[7]. Hawk JLM, Norris PG. Abnormal Responses to UV radiation. In: Freedberg IM, Eisen AZ, Wolff K, Austen KF, Goldsmith LA, Kats SI, editors, Fitzpatrick's Dermatology in General Medicine. $5^{\text {th }}$ ed. McGraw-Hill: New York;1999 Pg.1.1573-89.

[8]. Frain - Bell W, Dickson A, Herd J, Sturrock I et al. The action spectrum in polymorphic light eruption. Br J Dermatol $1973 ; 89: 243$.

[9]. Holzle EPML, Ewig G, von Kries R, Lehmann P. Polymorphous light eruption. J Invest Dermatol 1987;88:32S-38S.

[10]. Van praag MC, Boom BW, Vermeer BJ. Diagnosis and treatment of polymorphous light eruption. Int Dermatol 1994;33:233-239. 